\title{
Isoflurane causes concentration-dependent inhibition of medullary raphé 5-HT neurons in situ
}

Johansen $\mathrm{SL}^{\mathrm{a} 1}$, Iceman $\mathrm{KE}^{\mathrm{a} 2}$, Iceman $\mathrm{CR}^{\mathrm{b}}$, Taylor $\mathrm{BE}^{\mathrm{a}}$, and Harris $\mathrm{MB}^{\mathrm{a}}$

Running title: Isoflurane inhibits serotonergic neurons

${ }^{a}$ Institute of Arctic Biology, Department of Biology and Wildlife, University of Alaska, Fairbanks AK 99775, USA

${ }^{\mathrm{b}}$ Department of Chemistry and Biochemistry, University of Alaska, Fairbanks AK 99775, USA

Corresponding author: Michael B. Harris; mbharris@alaska.edu

${ }^{1}$ S. Johansen present address: School of Medicine, Stanford University, Stanford, CA 94305, USA ${ }^{2}$ K. Iceman's present address: Department of Molecular Pharmacology and Physiology, Morsani College of Medicine, University of South Florida, Tampa, FL 33612, USA 


\section{Introduction}

The cellular mechanisms and neuron types involved in producing the state of anesthesia, and associated decreases in autonomic activity, are largely undefined (Kotrly et al., 1984; Seagard et al., 1984; Pagel et al., 2007; Paisansathan et al., 2007). Serotonin-synthesizing (5-HT) neurons, primarily localized in the midline medulla, have widely distributed projections that influence homeostatic processes across the autonomic, motor, somatosensory, and limbic systems (Jacobs and Azmitia, 1992; Lovick 1997; Hornung 2003; Madden and Morrison, 2006). Serotonergic ascending projections to the forebrain mediate arousal, cognition, anxiety, and cerebral blood flow (Jacobs and Azmitia, 1992). Descending projections to the brainstem and spinal cord meditate respiratory, cardiovascular and motor control, thermoregulation, and nociception (Pérgola and Alper, 1992; Richerson 2004; Madden and Morrison, 2006; Watts et al., 2012). Investigation has shown anesthetic, analgesic, hypnotic, and immobilizing actions of volatile anesthetics such as isoflurane on post-synaptic receptor types that are targets of serotonergic projections (Franks and Lieb, 1994; Minami et al., 1997; Bardin et al., 2000; Campagna et al., 2003; Zhang et al., 2003; Mukaida et al., 2007; Nagatani et al., 2011). Although volatile anesthetics also influence presynaptic mechanisms that alter serotonergic neuron activity (Bayliss and Barrett, 2008; Orestes and Todorovic, 2010; Herold and Hemmings, 2012), such action is poorly understood and uncharacterized in intact nervous systems. One study demonstrated sensitivity of serotonergic neurons in vitro to various anesthetics, but omitted volatile anesthetics such as isoflurane (McCardle and Gartside, 2012). The influence of volatile anesthetics on 5-HT neurons is poorly understood and yet may contribute greatly to states of anesthesia.

Recently it has been demonstrated that there are distinct and specialized subsets of serotonergic neurons which may represent cells with intrinsic functional differences (Brust et al., 2014). One genetically 
defined subset of serotonergic neurons are intrinsically sensitive to $\mathrm{CO}_{2} / \mathrm{pH}$. We have recently shown that these $\mathrm{CO}_{2} / \mathrm{pH}$ sensitive $5 \mathrm{HT}$ neurons are severely hyperpolarized by isoflurane, suggesting a mechanism for ventilatory and chemosensory depression during anesthesia (Massey et al., 2015). In the present study, we specifically exclude this subset of neurons to investigate a potentially more general characteristic of isoflurane sensitivity. We previously characterized the firing patterns of conclusively identified 5-HT neurons in intact unanesthetized brainstem preparations using extracellular recordings, juxtacellular labeling, and immunohistochemistry (Johansen et al., 2012; Iceman et al., 2013; Iceman and Harris, 2014; Massey et al., 2015). Using these methods, we now test the hypothesis that 5-HT neurons are inhibited by isoflurane, and we speculate that such influence could contribute to the widespread actions of anesthesia.

\section{Methods}

\subsection{Experimental animals and preparations:}

All experiments were done in accordance with the National Institutes of Health "Guide for the Care and Use of Laboratory Animals" guidelines and were approved by the University of Alaska Fairbanks Institutional Animal Care and Use Committee. Juvenile male rats (50 - 150 g; Sprague-Dawley strain; Simonson Laboratories, Gilroy, CA, USA) were used to generate the perfused in situ brainstem preparation as previously described (Paton 1996; Johansen et al., 2012; Corcoran et al., 2013; Iceman et al., 2013; Iceman and Harris, 2014; Massey et al., 2015). Briefly, animals were administered an intraperitoneal heparin sodium injection (0.5 mL of 1000 i.u./mL; Baxter, Deerfield, IL, USA) and deeply anaesthetized with isoflurane. Preparations were bisected sub-diaphragmatically, decerebrated rostral to the superior colliculi, and immersed in chilled artificial cerebral spinal fluid for the remainder of the dissection. Subsequent procedures were conducted without anesthesia. 
Preparations were placed prone in the recording chamber. The descending aorta was cannulated retrogradely with a double-lumen catheter, and preparations were perfused with solution at a temperature of $31^{\circ} \mathrm{C}$. The perfusate solution contained the following (in mM): $1.0 \mathrm{MgSO}_{4}, 125$ $\mathrm{NaH}_{2} \mathrm{PO}_{4}, 4.0 \mathrm{KCl}, 24 \mathrm{NaHCO}_{3}, 115 \mathrm{NaCl}, 10 \mathrm{D}$-Glucose, 2.0 $\mathrm{CaCl}_{2}$, and 0.18 Ficoll. Under baseline conditions, the perfusate was equilibrated with $95 \% \mathrm{O}_{2}-5 \% \mathrm{CO}_{2}\left(\mathrm{PCO}_{2} 33 \mathrm{mmHg}\right.$; pH 7.4). The neuromuscular blocker gallamine triethidodide $(60 \mathrm{mg} / \mathrm{L})$ was added to the perfusate to eliminate movement. The pressure of aortic perfusion was gradually increased to $50-75 \mathrm{mmHg}$ and held constant.

\subsection{Extracellular recording and neuron selection:}

Extracellular recordings were conducted using pulled-glass capillary electrodes (15-30 M $\Omega$ ) filled with biotinamide hydrobromide (5\%; Life Technologies, Carlsbad, CA, USA) in $0.5 \mathrm{M}$ sodium acetate, as previously described (Iceman et al., 2013; Iceman and Harris, 2014). We targeted medullary raphé (r. magnus, r. obscurus, r. pallidus) neurons along the midline $(\leq 0.1 \mathrm{~mm}$ lateral $)$ between 0 and $3 \mathrm{~mm}$ rostral of obex. Extracellular recordings were made with an intracellular amplifier (Axon Instruments Multiclamp 700B) in current clamp mode, with a high pass filter at $300 \mathrm{~Hz}$ and low pass filter at $1 \mathrm{kHz}$ Bessel, using a high impedance headstage (Axon CV7B, Molecular Devices). Single unit action potentials were digitized at $25 \mathrm{kHz}$ using Spike 2 (Cambridge Electronic Design Power 1401) and LabChart (AD Instruments) software and stored as computer data files.

Cells were initially screened for being serotonergic by real-time assessment of firing frequency and regularity. Cells with firing patterns characteristic of serotonergic neurons (tonic firing without sustained pauses or phasic bursts at frequencies below $3 \mathrm{~Hz}$ ) were considered potential serotonergic neurons 
during experimental recording. Recordings of cells not matching these general criteria were not maintained. Neuronal recordings were initiated under baseline conditions (perfusate equilibrated with $95 \% \mathrm{O}_{2}-5 \% \mathrm{CO}_{2} ; \mathrm{PCO}_{2} 33 \mathrm{mmHg} ; \mathrm{pH}$ 7.4). These conditions approximate normocapnic plasma in vivo. Due to the lack of haemoglobin, solution hyperoxia $\left(\mathrm{PO}_{2} \sim 600 \mathrm{mmHg}\right)$ was necessary to maintain $\mathrm{O}_{2}$ content sufficient to meet tissue metabolic demands, and this unavoidable hyperoxia was constant under all conditions. We have previously considered the impact of isoflurane on the $\mathrm{CO}_{2}$-sensitive subset of 5-HT neurons (Johansen et al., 2012; Massey et al., 2015) and designed the current investigation to determine such impact on $\mathrm{CO}_{2}$-insensitive 5-HT cells. To exclude $\mathrm{CO}_{2}$-sensitive cells, once stable recordings were obtained, preparations were briefly exposed to perfusate equilibrated with $91 \% \mathrm{O}_{2}-9 \% \mathrm{CO}_{2}\left(\mathrm{PCO}_{2} 60 \mathrm{mmHg} ; \mathrm{pH} 7.2 ; 5 \mathrm{~min}\right)$. Cells that changed mean firing frequency by greater than 20\% were excluded from the current analysis (Johansen et al., 2012; Iceman et al., 2013; Massey et al., 2015). Cells were returned to baseline conditions for at least 5 min prior to experimental protocols.

\subsection{Isoflurane treatments:}

Isoflurane treatments were administered as previously described (Johansen et al., 2012). Isoflurane was bubbled into the perfusate for $10 \mathrm{~min}\left(1,1.5\right.$, or $2 \%$ isoflurane in $\left.95 \% \mathrm{O}_{2}-5 \% \mathrm{CO}_{2}\right) .1 \%$ isoflurane approximates $1.15 \%$, which is $1 \mathrm{MAC}$, the minimum alveolar concentration of isoflurane necessary for surgical anesthesia (Eger 1981). Upon return to baseline conditions (0\% isoflurane; $95 \% \mathrm{O}_{2}-5 \% \mathrm{CO}_{2}$ ), the neuron was allowed to recover toward its baseline firing frequency. 


\subsection{Juxtacellular labeling:}

Subsets of recorded neurons were individually filled with biotinamide using the juxtacellular labeling method, as previously described (Pinault 1996; Iceman et al., 2013; Iceman and Harris, 2014).

Extracellular recordings were conducted in current clamp mode (Axon Multiclamp 700B) to allow current to be injected through the electrode while action potentials were monitored. Positive current pulses (400-ms duration) were applied and gradually increased from 0-15 mV (0.5 mV steps) until cell discharge entrained to the stimulus for at least $30 \mathrm{~s}$, resulting in uptake of the ejected biotinamide by the recorded cell. After termination of entrainment, the biotinamide was allowed to disperse for $30 \mathrm{~min}$. Rats were perfused through the descending aorta with 4\% paraformaldehyde (in 0.1 M PBS). Brainstems were removed and stored in fixative overnight. Coronal sections $(60 \mu \mathrm{m})$ were cut through the medulla (Vibratome 1000Plus), and sections were processed free-floating.

\subsection{Immunohistochemistry:}

Tissue sections were first incubated in blocking buffer for $1 \mathrm{hr}$ at $20{ }^{\circ} \mathrm{C} \mathrm{(5 \%} \mathrm{normal} \mathrm{goat} \mathrm{serum,} 0.3 \%$ Triton X-100 in $0.1 \mathrm{M}$ PBS), then a streptavidin-Alexa 546 conjugate for $2 \mathrm{hr}$ at $20{ }^{\circ} \mathrm{C}$ (Life Technologies \#S-11225; 1:500 dilution in PBS with 5\% NGS) to reveal biotinamide introduced into single neurons by juxtacellular labeling. To identify serotonergic cells, sections were incubated overnight at $4{ }^{\circ} \mathrm{C}$ with mouse monoclonal anti-tryptophan hydroxylase (TPH) antibody (Sigma-Aldrich \#T0678; 1:1000 dilution in blocking buffer), then incubated for $2 \mathrm{hr}$ at $20^{\circ} \mathrm{C}$ in secondary goat antimouse Alexa 488 antibody (Life Technologies \#A-11029; 1:500 dilution in 0.1 M PBS with 5\% NGS). Fluorophores were individually excited and emission spectra collected separately to minimize interference using a Zeiss LSM510 confocal microscope: biotinamide-labeled neuron, Alexa 546, 543 
nm laser, filter BP 560-615; anti-TPH, Alexa 488, 488 nm laser, filter BP 505-530. Images are presented as 20x projections of z-stacks.

\subsection{Gas chromatography-mass spectrometry:}

All gas chromatography - mass spectrometry (GCMS) analyses were performed on an Agilent Technologies 7890A GC System and 5975C mass selective detector. Helium carrier gas was used at a constant flow rate of $20 \mathrm{~mL} \mathrm{~min}^{-1}$. Samples were injected into a DB-1 ms capillary column $(45 \mathrm{~m} \times 0.25$ $\mathrm{mm}$, film thickness $0.25 \mu \mathrm{m}$ ) at a split ratio of 50:1. The system oven temperature was initially maintained at $30{ }^{\circ} \mathrm{C}$ for $6 \mathrm{~min}$, and then increased at a rate of $10{ }^{\circ} \mathrm{C} \mathrm{min}{ }^{-1}$ from 30 to $120{ }^{\circ} \mathrm{C}$. MS acquisition was performed in full scan mode from 40 to 200 amu. Mass conditions were as follows: ionization voltage, $70.0 \mathrm{eV}$; ion source temperature, $230{ }^{\circ} \mathrm{C}$; detector voltage, $1.6 \mathrm{kV}$.

A saturated solution of isoflurane $(15 \mathrm{mM})$ was prepared by adding aliquots of isoflurane to perfusate solution and stirring in an airtight container for $3 \mathrm{hr}$ (Scheller et al., 1997). Different concentrations were prepared by diluting the saturated solution in perfusate $(1: 2,1: 4,1: 8,1: 16,1: 32$, and 1:64). Samples $(250 \mu \mathrm{L})$ of headspace gas from each dilution were analysed by GCMS for isoflurane intensity to generate a standard curve for isoflurane. The standard curve was fit to a linear regression line (SigmaPlot). Samples of perfusate were taken from the aortic cannula, to best approximate perfusate received by experimental preparations, at each minute during a 10-min 1\% isoflurane exposure. The GCMS headspace analysis of these samples yielded a value for mean peak area, corresponding to the number of isoflurane molecules in solution, and the concentration of isoflurane in solution at each minute of the drug exposure was calculated from the standard curve equation. In all cases the standard 
curve and perfusate samples were run in triplicates and average isoflurane peak area was used to determine concentration.

\subsection{Data analysis:}

Stable 1-2 min periods of individual unit firing were analysed (Spike 2; Spike Histogram, AD Instruments) before and during isoflurane treatment to provide a mean value for unit firing frequency (spikes/s) and interspike interval (ms). Paired $t$-tests or one-way ANOVA and post-hoc Holm-Sidak pairwise comparison tests were used to compare means (SigmaPlot). Values are expressed as mean \pm standard error of the mean. The criteria for statistical significance was $P<0.05$.

\subsection{Neuron classification:}

Putative serotonergic cells were identified based on an assessment of frequency and regularity of firing. In this assessment the mean interspike interval $(\bar{X})$ and standard deviation of the intervals (sd) are considered independent variables. The algorithm $\mathrm{Y}(\bar{X}, \mathrm{sd})=146-\bar{X}+0.98$ sd was used to characterize or exclude spontaneously firing neurons as serotonergic (Mason 1997). If the value of this function was less than zero $[\mathrm{Y}(\bar{X}, \mathrm{sd})<0]$, the cell was predicted to be serotonergic, while function values greater than zero $[\mathrm{Y}(\bar{X}, \mathrm{sd})>0]$ suggested the cell was non-serotonergic. All neurons selected for recording by realtime assessment of firing pattern and regularity were subsequently classified as putative serotonergic cells by the algorithm. 


\section{Results}

\subsection{Characteristics of medullary raphé 5-HT neurons.}

Cells were initially selected for firing characteristics expected of 5-HT neurons, including large spike width, long after-hyperpolarization, and regular firing with tonic frequencies below $3 \mathrm{~Hz}$ without sustained pauses or phasic bursts. Putative 5-HT neurons $(n=38)$ had baseline firing frequencies between 0.1 to $2.01 \mathrm{~Hz}$ and firing patterns consistent with serotonergic neuron characteristics. All neurons selected for recording were classified as putative 5-HT neurons by subsequent regularity assessment (Mason 1997). In our previous work, 5-HT neurons that exhibited the above firing characteristics were conclusively identified through juxtacellular labelling followed by immunohistochemical localization of the serotonin-synthesizing enzyme tryptophan hydroxylase (TPH) (Johansen et al., 2012; Iceman et al., 2013; Iceman and Harris, 2014).

\subsection{Isoflurane inhibits firing of medullary raphé 5-HT neurons.}

Single unit extracellular recordings performed on putative 5-HT neurons before, during, and after isoflurane treatment indicate that isoflurane inhibited the action potential discharge of these neurons. A subset of these neurons $(n=3)$ were juxtacellularly filled with biotinamide and confirmed as serotonergic by colocalization of TPH in the biotinamide-labeled neuron. A representative cell is shown in Figure 1. All recorded neurons were classified as putative 5-HT neurons by the algorithm that distinguishes between serotonergic and non-serotonergic cells (Mason 1997).

\subsection{Isoflurane inhibits firing of raphé 5-HT neurons at different concentrations.}

All preparations $(n=38$, one cell recorded per animal) received isoflurane at either $1 \%(n=18) ; 1.5 \%$ $(\mathrm{n}=10)$; or $2 \%(\mathrm{n}=10) .36$ of the 38 recorded cells $(95 \%)$ were inhibited or silenced by isoflurane. For 
2/38 cells, baseline firing either did not significantly change ( $7.89 \%$ increase) or significantly increased (48.0\% increase) in response to $1 \%$ isoflurane (data not shown). Mean baseline firing frequencies during $0 \%$ isoflurane ( $1 \%$ isoflurane: $0.964 \pm 0.11 \mathrm{~Hz} ; 1.5 \%$ isoflurane: $1.00 \pm 0.15 \mathrm{~Hz}$; and $2 \%$ isoflurane: $0.95 \pm 0.16 \mathrm{~Hz})$ for each treatment group were not significantly different $(P=0.971)$. The mean firing frequencies in the last minute of isoflurane exposure for each isoflurane dose (1\% isoflurane: $0.349 \pm$ $0.11 \mathrm{~Hz} ; 1.5 \%$ isoflurane: $0.113 \pm 0.04 \mathrm{~Hz}$; or $2 \%$ isoflurane: $0.021 \pm 0.01 \mathrm{~Hz}$ ) were each different from those under baseline conditions prior to isoflurane exposure $(P<0.001$, paired $t$-test $)$, indicating that isoflurane inhibits medullary raphé 5-HT neurons throughout the range of concentrations approximating MAC.

\subsection{Isoflurane-induced inhibition of raphé 5-HT neurons is concentration-dependent.}

The mean percent decrease of firing rate from baseline during isoflurane exposure was calculated for each isoflurane treatment group (1\% isoflurane: $-68.96 \pm 9.57 \% ; 1.5 \%$ isoflurane: $-89.78 \pm 3.52 \% ; 2 \%$ isoflurane: $-97.76 \pm 1.24 \%$ ). A comparison of these mean percent changes using one-way ANOVA indicated a significant difference between neurons receiving $1 \%$ and $2 \%$ isoflurane $(P<0.05)$, demonstrating that isoflurane-induced inhibition of putative 5-HT neurons was concentration-dependent (Fig. 2). The proportional changes induced by 1 versus $1.5 \%$ isoflurane were not significantly different $(P=0.147)$ and neither were the changes induced by $2 \%$ versus $1.5 \%$ isoflurane $(P=0.541)$.

\subsection{Presence of isoflurane in the perfusate confirmed by gas chromatography-mass spectrometry} analysis.

Aliquots of the perfusate sampled during administration of isoflurane were analysed by GCMS to confirm that the experimental preparation received the intended concentration of isoflurane via the 
perfusate. A chromatogram of a sample of $1 \%$ isoflurane in perfusion solution indicates two distinct peaks: $\mathrm{CO}_{2}$ and isoflurane (Fig. 3a). The peak at retention time 3.20 min was identified as isoflurane based on the mass spectra $\left(\mathrm{C}_{3} \mathrm{H}_{2} \mathrm{ClF}_{5} \mathrm{O}\right.$; molecular weight $\left.=184.49 \mathrm{~g} / \mathrm{mol}\right)$, which showed characteristic molecular and fragment ions: m/z $149\left(\mathrm{C}_{3} \mathrm{H}_{2} \mathrm{~F}_{5} \mathrm{O}-\mathrm{Cl}\right)$ and $116.9\left(\mathrm{C}_{2} \mathrm{HClF}_{3}-\mathrm{OCHF}_{2}\right)(\mathrm{Fig}$. 3b).

\subsection{Standard curve for isoflurane based on GCMS analysis of perfusate.}

A standard curve for isoflurane was generated from a saturated solution of isoflurane (15 mM) (Scheller et al., 1997). Dilutions of the saturated solution $(1: 2,1: 4,1: 8,1: 16,1: 32$, and 1:64) were analysed by GCMS. The mean peak area for each dilution, corresponding to the number of isoflurane molecules in solution, was used to generate the standard curve for isoflurane (Fig. 3c), which was fit to a linear regression line described by the following equation: $y=6.2 * 10^{6} \mathrm{x}+6.0^{*} 10^{5}\left(\mathrm{R}^{2}=0.994\right)$.

3.7 Isoflurane concentration in perfusate is equivalent to 1 volume percent. Isoflurane is poorly soluble in water, but readily soluble in plastic and rubber tubing (Eger 1981); thus, we confirmed the concentration of isoflurane received by the preparation through the perfusate using GCMS analysis. At $10 \mathrm{~min}$, the time point when all neuronal responses to isoflurane were recorded, the mean equilibrium isoflurane concentration was $0.38 \mathrm{mM}$, which was equivalent to 1 volume percent (Fig. $3 \mathrm{~d} ; 0.38 \mathrm{mM}=$ mean concentration from 6 to $10 \mathrm{~min} ; 0.37 \mathrm{mM}=1$ volume percent; Eilers et al., 1999). The 6 to $10 \mathrm{~min}$ range was chosen to calculate the mean equilibrium concentration because the concentration steadily increased from 3 to $6 \mathrm{~min}$ and remained relatively constant from 6 to $10 \mathrm{~min}$. Additional samples taken at 11 and 15 min demonstrate stability throughout the recording period. 


\section{Discussion}

In conjunction with our earlier characterization of isoflurane-sensitivity of specifically $\mathrm{CO}_{2}$-stimulated 5-HT neurons, we present the first evidence that isoflurane inhibits firing of caudal raphé $\mathrm{CO}_{2}-$ insensitive 5-HT neurons. Isoflurane routinely inhibited 5-HT neuron discharge, or caused firing to cease completely (Fig. 1). The degree of inhibition increased as the concentration of isoflurane in the perfusion solution increased, and the difference between neuronal responses to 1 and $2 \%$ isoflurane indicated concentration-dependent responsiveness of putative 5-HT neurons to isoflurane within a clinically relevant range (Fig. 2). The observed trend toward significant inhibition in the 1 to $1.5 \%$ comparison group with little evidence for further inhibition in the 1.5 to $2 \%$ comparison may be due to neuronal activity reaching maximal inhibition at $1.5 \%$ isoflurane. $1 \%$ isoflurane approximated $1 \mathrm{MAC}$ (confirmed by GCMS analysis; Fig. 3), the minimum alveolar concentration of isoflurane necessary for surgical anesthesia (Eger 1981), which allowed us to confirm that our preparations received isoflurane at clinically relevant concentrations.

We have previously reported that isoflurane hyperpolarizes and inhibits/abolishes the tonic firing of a distinct subset of $\mathrm{CO}_{2}$-sensitive 5-HT neurons (Massey et al. 2015), and here illustrate similar isoflurane-mediated inhibition of $\mathrm{CO}_{2}$-insensitive neurons. Both of these cell types fire in a manner expected of 5HT neurons (Mason 1997). Importantly, there are populations of 5-HT neurons that do not fire with this expected discharge pattern. These, as well as non-5-HT neurons, have not been assessed for sensitivity to isoflurane. As such, we cannot conclude that isoflurane sensitivity is either a universal or exclusive feature of 5HT neurons. Isoflurane binds to two-pore domain potassium (TASK) channels (Bayliss and Barrett, 2008), which mediate instantaneous open-rectifier background K+ currents that are potentiated by volatile anesthetics, resulting in hyperpolarization. (Sirois et al., 1998; Patel et al., 1999; 
Sirois et al., 2000; Talley et al., 2000). Two subtypes of TASK channels, TASK-1 and TASK-3, are highly expressed in the raphé nuclei (70-90\% of 5HT neurons) compared to other brain regions (Talley et al., 2001; Washburn et al., 2002). We postulate that potentiation of the TASK channel-mediated background $\mathrm{K}+$ current by isoflurane may have hyperpolarized our target population of raphé 5-HT neurons. Isoflurane sensitivity may be absent in cells lacking TASK channels, and would be expected in any cell type that expresses these channels.

Many studies on the influence of anesthetics on 5-HT neurons have focused on molecular action at postsynaptic 5-HT receptors (Minami et al., 1997; Bardin et al., 2000; Mukaida et al., 2007; Nagatani et al., 2011). Our demonstration that isoflurane inhibits action potential generation in 5-HT neurons suggests that isoflurane acts on presynaptic sites, a hypothesis that, until recently (Griffiths and Norman, 1993; Pocock and Richards, 1993), has been overshadowed by consideration of postsynaptic anesthetic effects. Presynaptic binding sites for volatile anesthetics have been reported (Orestes and Todorovic, 2010; Herold and Hemmings, 2012; Hemmings 2009). Blockade of $\mathrm{Na}^{+}$channels (Wu 2004; Ouyang and Hemmings, 2005) and inhibition of $\mathrm{Ca}^{2+}$ currents (Study 1994; Nikonorov et al., 1998; Kamatchi et al., 1999) by anesthetics can inhibit action potential conductance and depress neurotransmitter release. The influence of isoflurane on these channels could also contribute to the inhibition of action potential discharge of 5-HT neurons by isoflurane.

The effect of anesthetics on 5-HT neuron activity in the dorsal raphé ascending system that mediates arousal, cognition, anxiety, and cerebral blood flow has been characterized (McCardle and Gartside, 2012), but the effect of anesthetics on 5-HT neurons in the caudal raphé descending system remains a pertinent question. This caudal raphé population of 5-HT neurons that we targeted mediates autonomic 
output, respiratory, cardiovascular and motor control, and nociception (Richerson 2004). Inhibition of this serotonergic system by isoflurane may contribute to the immobilization, hypnosis, sedation, analgesia, and cardiorespiratory depression characteristic of isoflurane anesthesia (Minami et al., 1997; Bardin et al., 2000; Mukaida et al., 2007; Nagatani et al., 2011).

In summary, we demonstrate that exposure to isoflurane inhibits 5-HT neuron firing in a concentrationdependent manner. Our work contributes to the growing body of literature that identifies presynaptic sites as critical components in mechanisms of anesthetic action. As 5-HT neurons have broad modulatory and homeostatic effects, isoflurane influences on these neurons could contribute to widespread actions of anesthesia.

Acknowledgements: S.L.J., K.E.I., M.B.H., and C.R.I. conception and design of research; S.L.J. and K.E.I. performed all electrophysiology experiments; C.R.I. and S.L.J. performed GC-MS experiments; S.L.J analysed data; S.L.J., K.E.I., B.E.T and M.B.H. interpreted results of experiments; S.L.J. prepared figures; S.L.J. drafted manuscript; S.L.J., K.E.I., B.E.T and M.B.H. edited and revised manuscript; S.L.J., K.E.I., B.E.T, M.B.H., and C.R.I. approved final version of manuscript.

\section{Declaration of interests: None.}

Funding: This research was funded by the National Science Foundation (IOS 1022442, BET), and the National Institutes of Health through awards from the National Institutes of Neurological Disorders and Stroke under award number 2U54NS041069 (MBH and BET), the National Institute of General Medical Sciences under award SC2GM112570 (MBH) and an Institutional Development Award (IDeA) from the 
National Institute of General Medical Sciences under award number P20GM103395. The content is solely the responsibility of the authors and does not necessarily represent the official views of the NSF or NIH.

\section{References}

Bardin, L., Lavarenne, J., et al., 2000. Serotonin receptor subtypes involved in the spinal antinociceptive effect of 5-HT in rats. Pain 86 (1-2), 11-8.

Bayliss, D.A., Barrett, P.Q., 2008. Emerging roles for two-pore-domain potassium channels and their potential therapeutic impact. Trends Pharmacol Sci. 29 (11), 566-75.

Brust RD, Corcoran AE, Richerson GB, Nattie E, Dymecki SM. 2014. Functional and developmental identification of a molecular subtype of brain serotonergic neuron specialized to regulate breathing dynamics. Cell Rep. 9(6):2152-65.

Campagna, J.A., Miller, K.W., et al., 2003. Mechanisms of actions of inhaled anesthetics. N Engl J Med. $348(21), 2110-24$.

Corcoran, A.E., Richerson, G.B., et al., 2013. Serotonergic mechanisms are necessary for central respiratory chemoresponsiveness in situ. Respir Physiol Neurobiol. 186 (2), 214-20.

Eger, E.I., 1981. Isoflurane: a review. Anesthesiology 55 (5), 559-76.

Eilers, H., Kindler, C.H., et al., 1999. Different effects of volatile anesthetics and polyhalogenated alkanes on depolarization-evoked glutamate release in rat cortical brain slices. Anesth Analg. 88 (5), $1168-74$.

Franks, N.P., Lieb W.R., 1994. Molecular and cellular mechanisms of general anesthesia. Nature 367 (6464), 607-14. 
Griffiths, R. Norman, R.I., 1993. Effects of anesthetics on uptake, synthesis and release of transmitters. Br J Anaesth. 71 (1), 96-107.

Hemmings, H.C., 2009. Sodium channels and the synaptic mechanisms of inhaled anesthetics. Br J Anaesth. 103 (1), 61-9.

Herold, K.F., Hemmings, H.C., 2012. Sodium channels as targets for volatile anesthetics. Front Pharmacol. 3, 50.

Hornung, J.P., 2003. The human raphé nuclei and the serotonergic system. J Chem Neuroanat. 26, 33143.

Iceman, K.E., Richerson, G.B., et al., 2013. Medullary serotonin neurons are $\mathrm{CO}_{2}$-sensitive in situ. J Neurophysiol. 110 (11), 2536-44.

Iceman, K.E., Harris, M.B., 2014. A group of non-serotonergic cells is $\mathrm{CO}_{2}$-stimulated in the medullary raphé. Neuroscience 259, 203-13.

Jacobs, B.L., Azmitia, E.C., 1992. Structure and function of the brain serotonin system. Physiol Rev. 72 (1), 165-299.

Johansen, S.L., Iceman, K.E., et al., 2012. Influence of isoflurane on $\mathrm{CO}_{2}$ sensitive and insensitive raphé neurons. Program No. 897.08. Neuroscience Meeting Planner. New Orleans, LA: Society for Neuroscience. Online.

Kamatchi, G.L., Chan, C.K., et al., 1999. Volatile anesthetic inhibition of neuronal $\mathrm{Ca}^{2+}$ channel currents expressed in Xenopus oocytes. Brain Res. 831 (1-2), 85-96.

Kotrly KJ, Ebert TJ, Vucins E, Igler FO, Barney JA, Kampine JP.,1984. Baroreceptor reflex control of heart rate during isoflurane anesthesia in humans. Anesthesiology. 60(3):173-9.

Lovick, T.A., 1997. The medullary raphé nuclei: a system for integration and gain control in autonomic and somatomotor responsiveness? Exp Physiol. 82 (1), 31-41. 
Madden, C.J., Morrison, S.F., 2006. Serotonin potentiates sympathetic responses evoked by spinal NMDA. J. Physiol. 577(2); 525-537.

Mason, P., 1997. Physiological identification of pontomedullary serotonergic neurons in the rat. J Neurophysiol. 77 (3), 1087-98.

Massey, C.A., Iceman, K.E., et al., 2015. Isoflurane abolishes spontaneous firing of serotonin neurons and masks their pH/CO2 chemosensitivity. J Neurophysiol. 113 (7), 2879-88.

McCardle, C.E., Gartside, S.E., 2012. Effects of general anesthetics on 5-HT neuronal activity in the dorsal raphé nucleus. Neuropharmacology 62 (4), 1787-96.

Minami, K., Minami, M., et al., 1997. Inhibition of 5-hydroxytryptamine type 2A receptor-induced currents by n-alcohols and anesthetics. J Pharmacol Exp Ther. 281 (3), 1136-43.

Mukaida, K., Schichino, T., et al., 2007. Activity of the serotonergic system during isoflurane anesthesia. Anesth Analg. 104 (4), 836-9.

Nagatani, H., Oshima, T., et al., 2011. Blockade of 5-HT(2A) and/or 5-HT(2C) receptors modulates sevoflurane-induced immobility. J Anesth. 25 (2), 225-8.

Nikonorov, I.M., Blanck, T.J., et al., 1998. The effects of halothane on single human neuronal L-type calcium channels. Anesth Analg. 86 (4), 885-95.

Orestes, P., Todorovic, S.M., 2010. Are neuronal voltage-gated calcium channels valid cellular targets for general anesthetics? Channels (Austin) 4 (6), 518-22.

Ouyang, W., Hemmings, H.C., 2005. Depression by isoflurane of the action potential and underlying voltage-gated ion currents in isolated rat neurohypophysial nerve terminals. J Pharmacol Exp Ther. $312(2), 801-8$. 
Pagel P.S., Kampine J.P., Schmeling W.T., Warltier D.C., 1991. Comparison of the systemic and coronary hemodynamic actions of desflurane, isoflurane, halothane, and enflurane in the chronically instrumented dog. Anesthesiology. 74(3):539-51.

Paisansathan C, Hoffman WE, Lee M, Ananda RC, Wheeler P., 2007. Autonomic activity during desflurane anesthesia in patients with brain tumors. J Clin Monit Comput. 21(5):265-9.

Patel, A.J., Honore, E., et al., 1999. Inhalational anesthetics activate two-pore-domain background $\mathrm{K}^{+}$ channels. Nat Neurosci. 2 (5), 422-6.

Paton, J.F., 1996. A working heart-brainstem preparation of the mouse. J Neurosci Methods. 65 (1). $63-$ 8.

Pérgola P.E, Alper R.H., 1992; Effects of central serotonin on autonomic control of heart rate in intact and baroreceptor deficient rats. Brain Res. 582(2):215-20.

Pinault, D., 1996. A novel single-cell staining procedure performed in vivo under electrophysiological control: morpho-functional features of juxtacellularly labeled thalamic cells and other central neurons with biocytin or Neurobiotin. J Neurosci Methods. 65 (2), 113-36.

Pocock, G., Richards, C.D., 1993. Excitatory and inhibitory synaptic mechanisms in anesthesia. Br J Anaesth. 71 (1), 134-47.

Richerson, G.B., 2004. Serotonergic neurons as carbon dioxide sensors that maintain $\mathrm{pH}$ homeostasis. Nat Rev Neurosci. 5 (6), 449-61.

Scheller, M., Bufler, J., et al., 1997. Isoflurane and sevoflurane interact with the nicotinic acetylocholine receptor channels in micromolar concentrations. Anesthesiology 86 (1), 118-27.

Seagard JL, Hopp FA, Bosnjak ZJ, Osborn JL, Kampine JP., 1984. Sympathetic efferent nerve activity in conscious and isoflurane-anesthetized dogs. Anesthesiology. 1984 Sep;61(3):266-70. 
Sirois, J.E., Lei, Q., et al., 2000. The TASK-1 two-pore domain $\mathrm{K}^{+}$channel is a molecular substrate for neuronal effects of inhalation anesthetics. J Neurosci. 20 (17), 6347-54.

Sirois, J.E., Pancrazio, J.J., et al., 1998. Multiple ionic mechanisms mediate inhibition of rat motoneurones by inhalation anesthetics. J Physiol (Lond). 512, 851-62.

Study, R.E., 1994. Isoflurane inhibits multiple voltage-gated calcium currents in hippocampal pyramidal neurons. Anesthesiology 81 (1), 104-16.

Talley, E.M., Lei, Q., et al., 2000. TASK-1, a two pore domain $\mathrm{K}^{+}$channel, is modulated by multiple neurotransmitters in motoneurons. Neuron 25, 399-410.

Talley, E.M., Solorzano, G., 2001. CNS distribution of members of the two-pore-domain (KCNK) potassium channel family. J Neurosci. 21 (19), 7491-505.

Washburn, C.P., Sirois, J.E., et al., 2002. Serotonergic raphé neurons express TASK channel transcripts and a TASK-like $\mathrm{pH}$ - and halothane-sensitive $\mathrm{K}^{+}$conductance. J Neurosci. 22 (4), 1256-65.

Watts, S.W, Morrison, S.F., Davis R. P., Barman S.M., 2012. Serotonin and Blood Pressure Regulation. Pharmacological rev. 64(2): 359-388.

Wu, X., Sun, J., et al., 2004. Isoflurane inhibits transmitter release and the presynaptic action potential. Anesthesiology 100 (3), 663-70.

Zhang, Y., Laster, M.J., et al., 2003. Blockade of 5-HT2A receptors may mediate or modulate part of the immobility produced by inhaled anesthetics. Anesth Analg. 97 (2), 475-9.

\section{Figure legends}

Figure 1. Medullary raphé 5-HT neurons are inhibited by isoflurane. a) Representative extracellular recording of a 5-HT neuron that ceased firing during isoflurane treatment. The neuron returned to baseline firing rate upon washout. Under baseline conditions, firing frequency $(1.12 \mathrm{~Hz})$ and pattern was 
characteristic of serotonergic cells. Scale bar $=30 \mathrm{~s}$. b) The same neuron was entrained to fire simultaneously with an applied stimulus and filled with biotinamide. c) Positive staining for TPH (green) and biotinamide (red) colocalize (yellow) to indicate the recorded neuron was serotonergic. Scale bar $=50 \mu \mathrm{m}$.

\section{Figure 2. Isoflurane-induced inhibition of raphé 5-HT neurons is concentration- dependent.} Values presented are mean percent decrease from baseline for each isoflurane concentration [1\% $(n=18) ; 1.5 \%(n=10) ;$ or $2 \%(n=10)]$. Between groups comparison of percent change from baseline during isoflurane exposure indicated that $2 \%$ isoflurane produced greater inhibition than $1 \%$ isoflurane (one-way ANOVA; $* P<0.05$ ).

Figure 3. Isoflurane concentration in perfusate is confirmed by gas chromatography - mass spectrometry analysis. a) Chromatogram of $1 \%$ isoflurane in perfusate solution. b) Mass spectra identified peak at retention time $3.20 \mathrm{~min}$ as isoflurane. c) Standard curve for isoflurane followed a linear regression line described by the equation: $y=6.2 * 10^{6} x+6.0^{*} 10^{5}\left(\mathrm{R}^{2}=0.994\right)$. e) GC-MS analysis of perfusate samples during $1 \%$ isoflurane treatment confirmed that at $10 \mathrm{~min}$, isoflurane concentration was equivalent to 1 volume percent. 
A

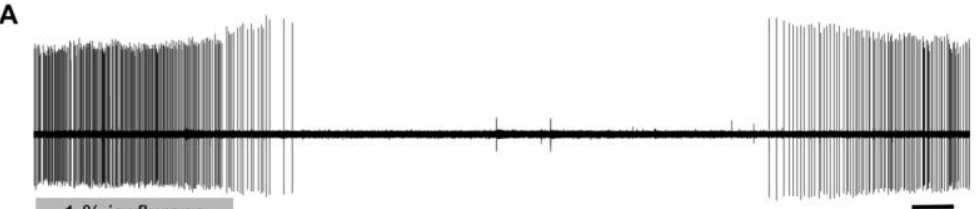

B

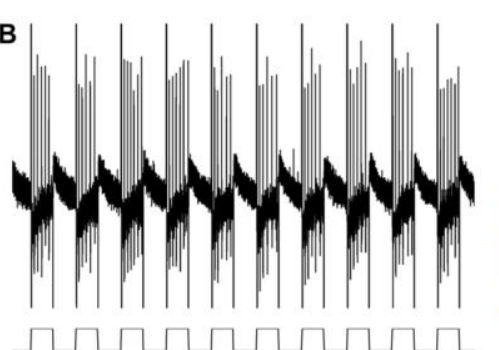

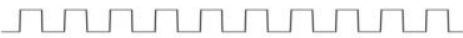

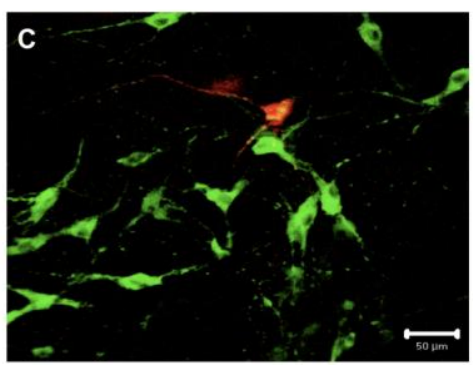

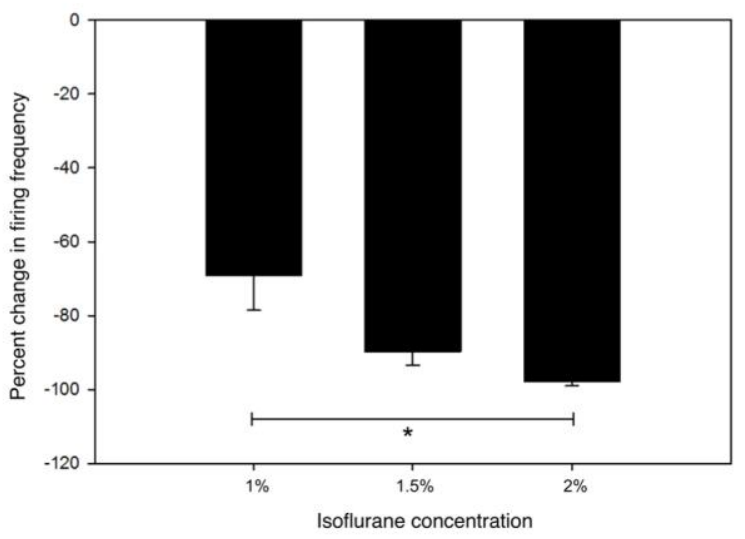

Figure 1 


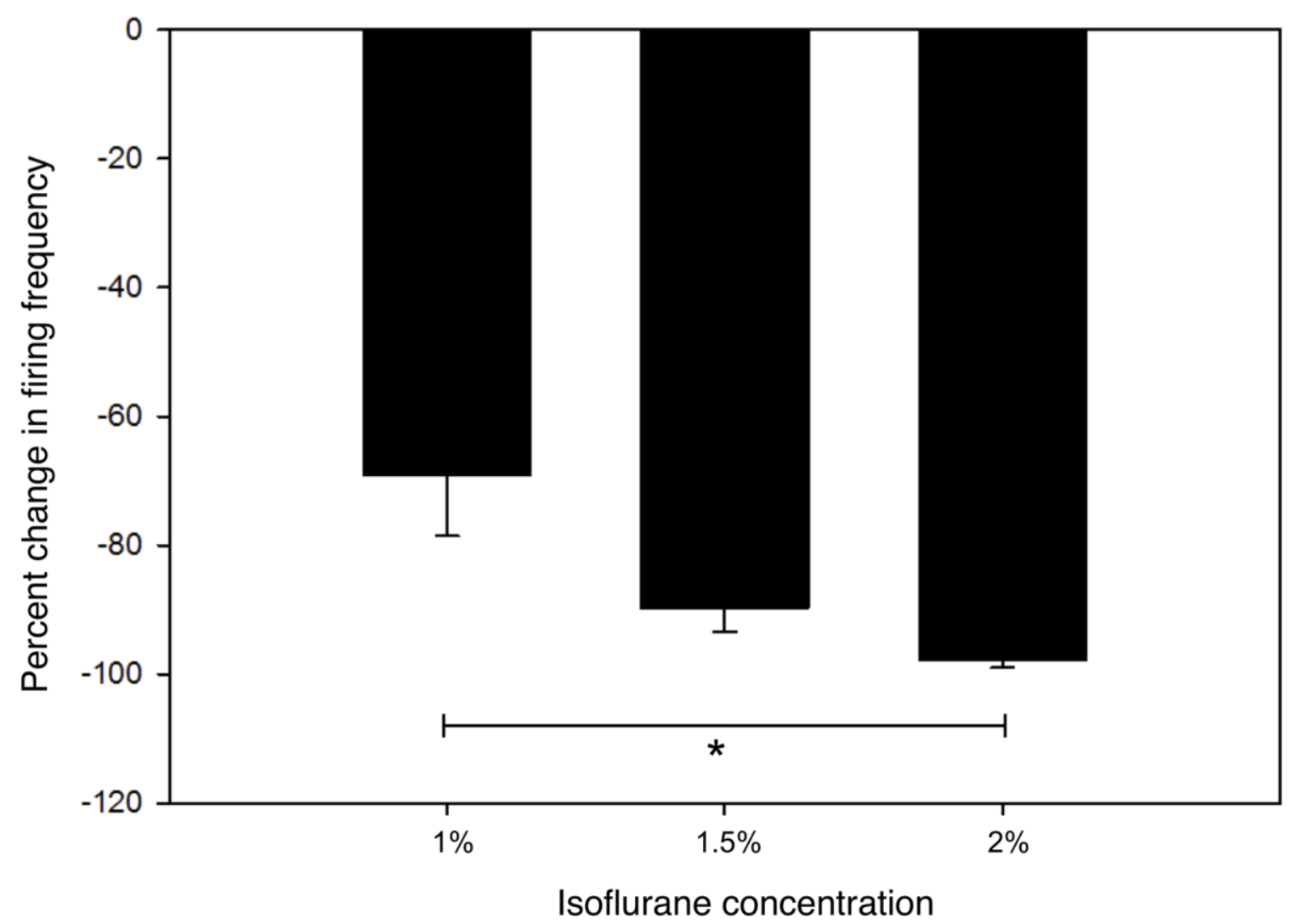

Figure 2 


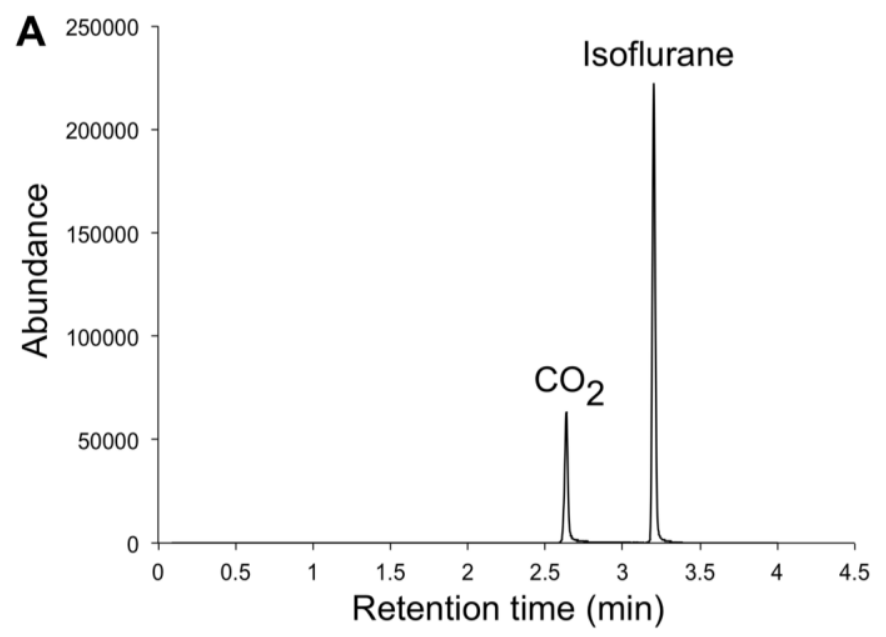

Isoflurane $\left(\mathrm{C}_{3} \mathrm{H}_{2} \mathrm{ClF}_{5} \mathrm{O}\right)$ Molecular weight: $184.49 \mathrm{~g} / \mathrm{mol}$
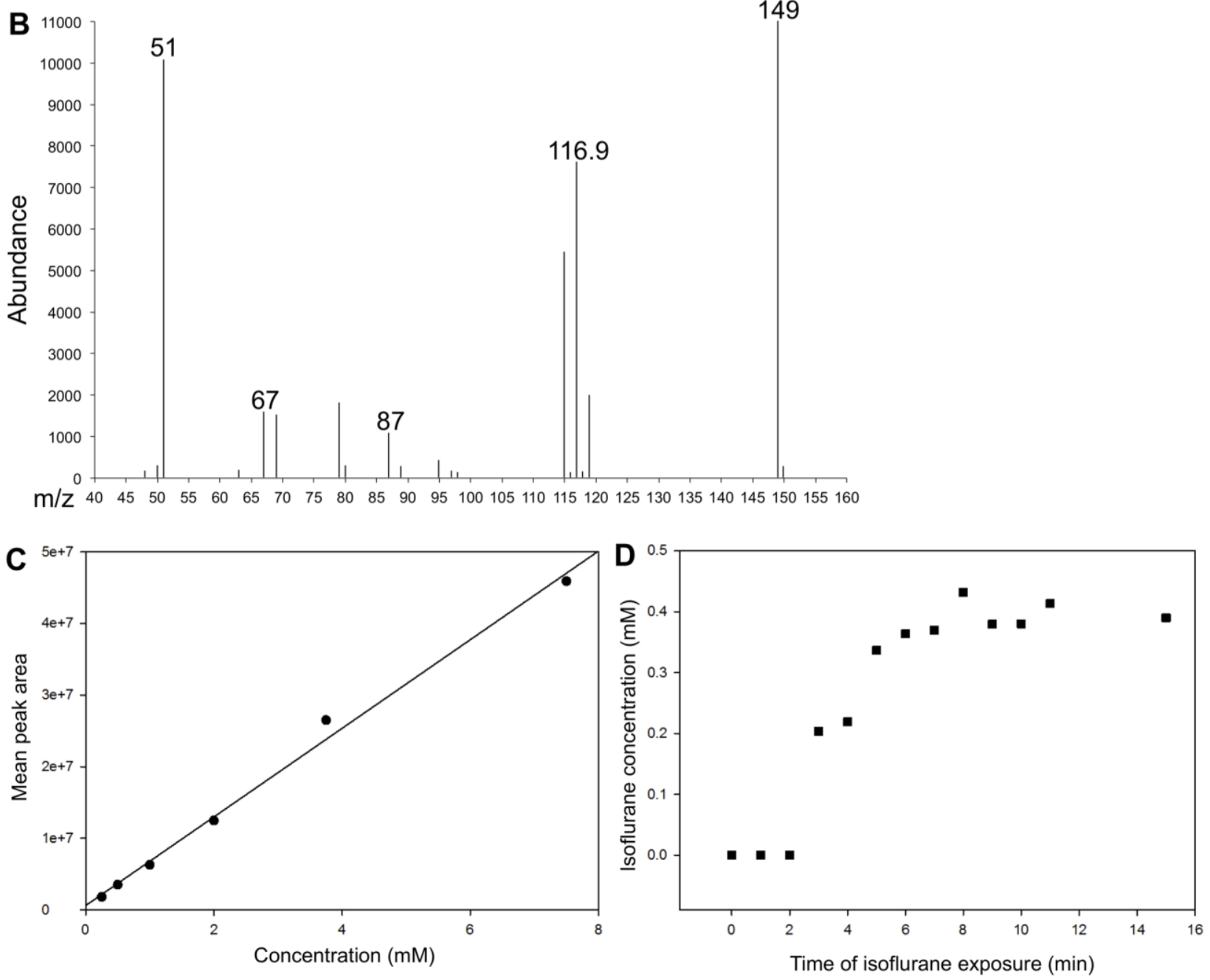

Figure 3 